\title{
A BASE MATEMÁTICA NOS ANOS INICIAIS: A REALIDADE DE UM ENSINO DEFASADO
}

\section{THE MATHEMATICAL BASIS IN INITIAL YEARS: THE REALITY OF DEFECTED TEACHING}

Francisca Maria dos Santos Osório ${ }^{1}$; Lino Cardoso Assunção Filho²; Marcos da Silva Ferreira $^{3}$; Fernanda Mary de Souza Fernandes ${ }^{4}$; Francismar Holanda ${ }^{5}$

\section{INTRODUÇÃO}

A Matemática é uma disciplina "temida" não só no ambiente escolar, mas também por grande parte da população.

Ao ingressarmos na vida escolar, lá nas séries iniciais, o primeiro contato com a matemática é entender os números, aprender a contar de um até dez, depois até vinte, até trinta, e assim sucessivamente. Então ao avançarmos, somos apresentados às quatro operações básicas da aritmética: adição, subtração, multiplicação e divisão. Sem essa base torna-se impossível compreender o próximo nível da disciplina.

O presente trabalho tem por objetivo apresentar os resultados da pesquisa realizada referente às quatro operações básicas e relatar a realidade de forma sucinta no que diz respeito à aprendizagem da base matemática nos anos iniciais, e mostrar a importância da formação dos professores das series iniciais, os quais ensinam a denominada alfabetização matemática. .

\section{FUNDAMENTAÇÃO TEÓRICA}

O desenvolvimento matemático nada mais é do que uma construção do conhecimento. Sem uma base forte e consolidada o desenvolvimento do ensino-aprendizagem, seja em qualquer área do conhecimento, estará fadado ao fracasso.

Nos anos iniciais espera-se que os alunos desenvolvam a chamada "Alfabetização Matemática”, termo utilizado para definir a aprendizagem matemática nos anos iniciais da vida acadêmica.

O conceito de Alfabetização matemática foi apresentado por Ocsana Danyluk,

refere-se aos atos de aprender a ler e a escrever a linguagem matemática usada nas primeiras séries da escolarização. Ser alfabetizado em matemática é entender o que se lê e escrever o que se entende a respeito das primeiras noções de aritmética, de geometria e da lógica (DANYLUK, 1998, p.14).

Pesquisas indicam que professores das series iniciais escolhem essa "modalidade" de

\footnotetext{
${ }^{1}$ Licenciatura em Matemática, IFPI, fr-osorio@ hotmail.com

${ }^{2}$ Licenciatura em Matemática, IFPI, linofilho08@gmail.com

${ }^{3}$ Licenciatura em Matemática, IFPI, msf.ifpi@gmail.com

${ }^{4}$ Licenciatura em Matemática, IFPI, fernandamary-sf@ hotmail.com

${ }^{5}$ Mestre, IFPI, frholanda@ifpi.edu.br
} 
ensino devido ao descontentamento que possuem com a matemática, porém estes mesmos professores precisam estar preparados para transmitir conhecimentos matemáticos entrando em contradição com a opção escolhida para o Magistério.

De acordo com Machado (1990, p.15):

[...] a Matemática faz parte dos currículos desde os primeiros anos da escolaridade, ao lado da Língua Materna. Há um razoável consenso com relação ao fato de que ninguém pode prescindir completamente de Matemática e, sem ela, é como se a alfabetização não se tivesse completado.

Quando as aulas são voltadas para as coisas prontas e definitivas, sem compreensão do significado contextualizado e sem a construção do conhecimento, os alunos fazem sem realmente compreender e esquecem facilmente quando deixam de fazer. Segundo Piaget citado por Pires (2006, p.24) é preciso levar os alunos a reinventar aquilo que é capaz, ao invés de se limitar a ouvir e repetir.

O ensino da base matemática é fundamental para o aluno e posterior entendimento da disciplina, pois formam uma base para as demais séries, que serão utilizadas futuramente, ao longo de sua vida escolar. É necessário orientar o ensino desta disciplina nos anos iniciais de modo a torná-la uma experiência escolar de sucesso.

\section{METODOLOGIA}

O principal método empregado para esta obra foi do tipo quantitativa. Para tanto, são especificados, a seguir, os instrumentos de pesquisa utilizados e os procedimentos adotados.

Para atender aos objetivos do trabalho, foi realizada uma pesquisa com 100 (cem) pessoas, com uma faixa etária a partir dos 15 anos de idade, através de um questionário eletrônico encaminhado aos entrevistados por intermédio das mídias sociais.

Em uma segunda etapa foi realizada uma avaliação matemática, a qual constava sentenças contento apenas as quatro operações básicas, sendo operações com 2, 3 e quatro algarismos, realizada com alunos do $9^{\circ}$ ano, da Fundação Nossa Senhora da Paz, escola publica do município de Teresina/PI, as quais fazem parte de um projeto realizado pelo Instituto Federal do Piau, Pré-Técnico do IFPI, que dispõe de aulas de português e matemática, como um prévestibular, para alunos que irão realizar o teste para ingressar no Ensino Médio, no Instituo Federal do Piaui.

Por fim foi realizada a análise quantitativa que foi fundamental para a compreensão da natureza dos fatos.

\section{RESULTADOS E DISCUSSÃO}


Após a coleta dos dados da pesquisa e da aplicação da avaliação obtivemos os seguintes resultados:

Em relação á dificuldade de resolver as quarto operações básicas, 93\% dos entrevistados afirmaram possuir dificuldade em pelo menos uma das quatro operações, como mostra o gráfico 1, e desses $61 \%$ afirmaram possuir dificuldade na resolução de sentenças que contenham divisão, $22 \%$ tem dificuldade em resolver multiplicações, $5 \%$ em adição e $5 \%$ em subtração.

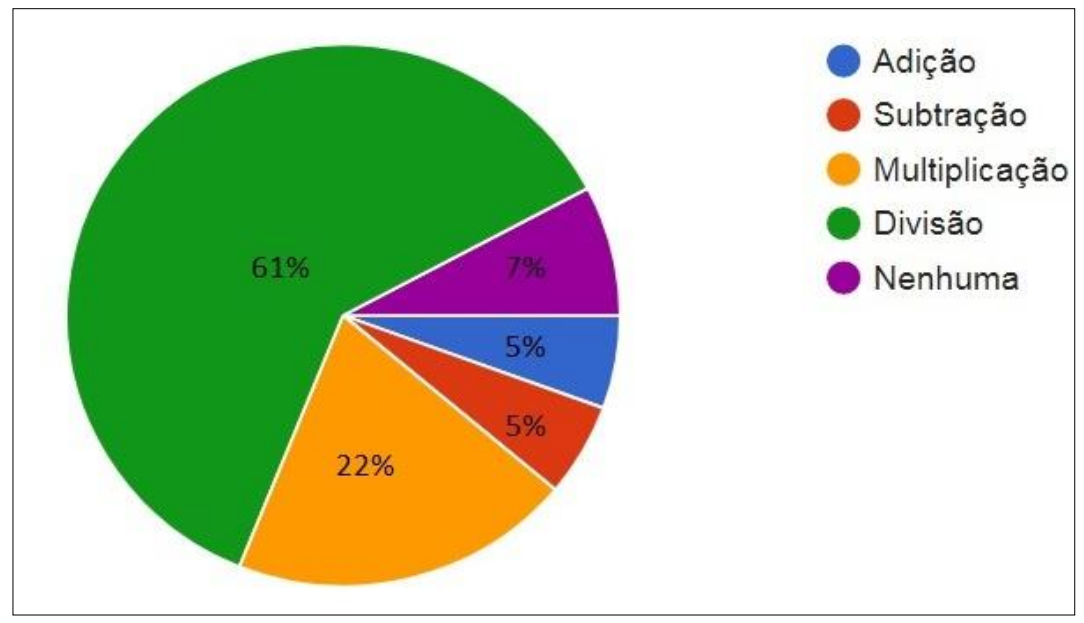

Grafico1: Dificuldade na resolução das quatro operações básicas. Fonte: Própria

Pode-se observar que, o ensino da base matemática foi defasado, pois, todos os entrevistados possuem um grau de escolaridade onde se deveria, pelo mesmo, saber resolver as quatro operações básicas, sendo que, apenas $15 \%$ dos entrevistados possuíam Ensino Fundamental Incompleto, como mostra o gráfico 2.

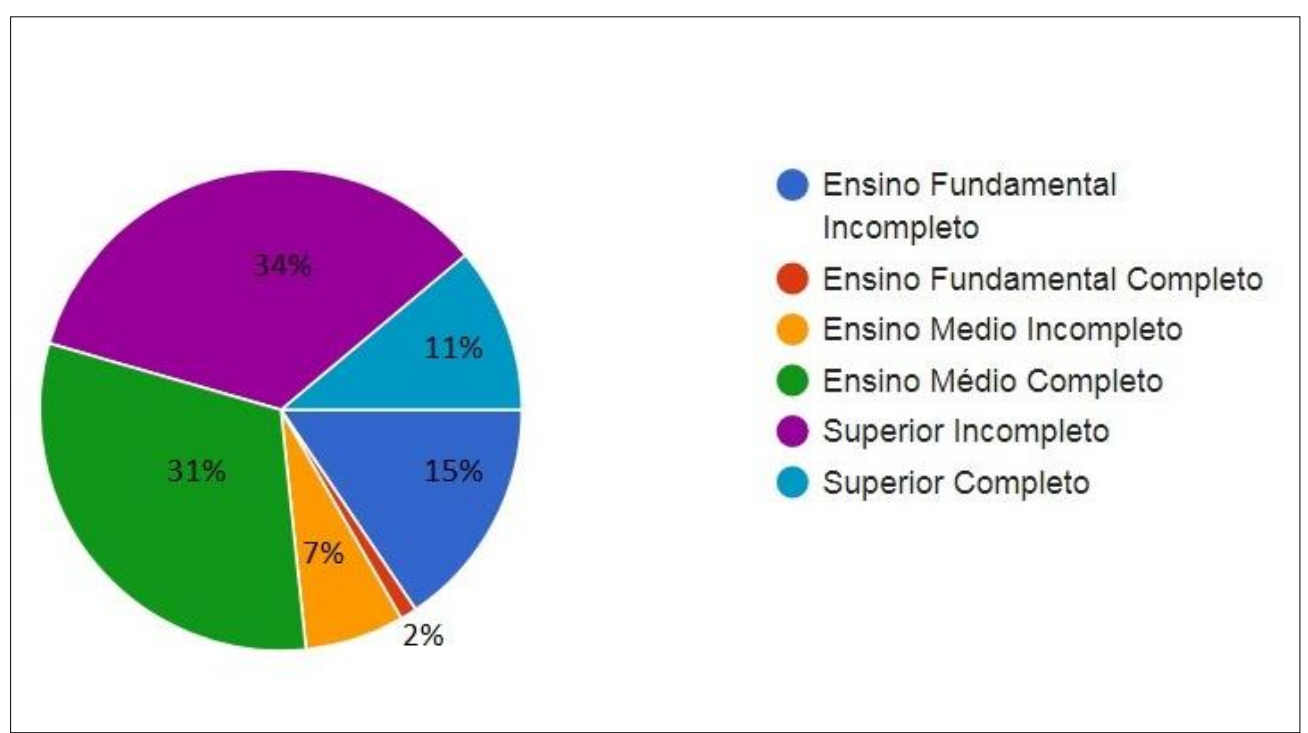




\section{Gráfico 2: Grau de Escolaridade. Fonte: Própria}

Sabe-se que devemos ter uma boa base para desempenhar qualquer atividade, e mesmo os $11 \%$, que possuem um Ensino Superior Completo, não possuem conhecimento total das quatro operações básicas o que nos mostra que, a matemática, necessária em qualquer curso superior, não foi aprendida e sim decorada apenas com a finalidade de passar de ano.

Em relação aos alunos do $9^{\circ}$ ano, os quais resolveram um teste que continha as quatro operações básicas, a grande maioria não soube responder operações de divisão com até quatro algarismos, como mostra o gráfico 3.

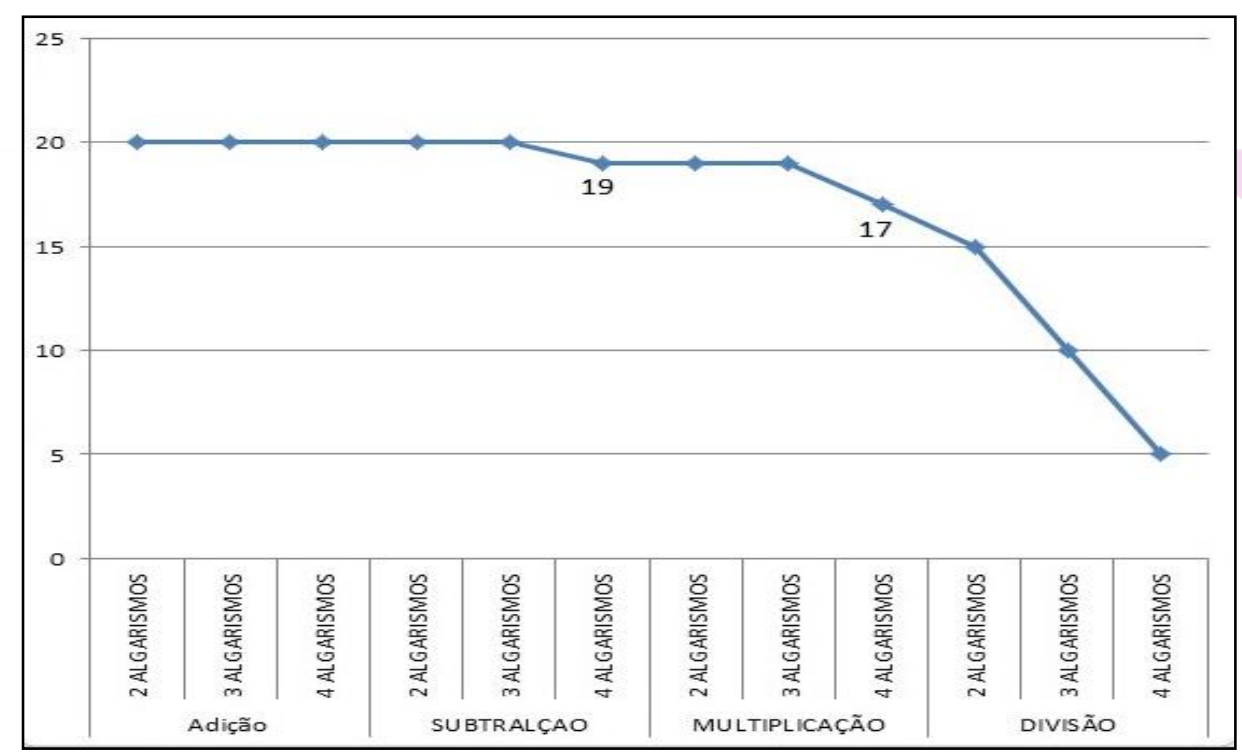

Gráfico 3: Grau de Escolaridade. Teste das Quatro operações Básicas. Fonte: Própria

Como mencionado anteriormente, os alunos que foram submetidos à avaliação fazem parte de um projeto Pré-Técnico, oferecido pelo IFPI, onde Graduandos de Licenciatura em Matemática oferecem aulas para reforçar a aprendizagem na disciplina aos alunos que irão fazer o teste para ingressar no ensino médio, porém, o que se observa é que, como não há um entendimento total na resolução de operações básicas, ou seja, a aprendizagem da base da matemática é insuficiente, fica impossível ensinar os demais fundamentos da disciplina, fazendo com que esta tenha baixo nível de aprendizado em todas as series do ensino.

\section{CONCLUSÕES}

Os anos iniciais da escolaridade tem grande importância para a vida do educando, principalmente quanto aos conceitos e relações em Matemática, porém o ensino dessa disciplina nesses anos iniciais torna-se, na maioria das vezes, defasado, onde a matemática é vista apenas como mais um estudo para passar de ano.

São inúmeros os exemplos citados de alunos que, mesmo concluindo o ensino médio, 
ou mesmo já terminando uma graduação, têm dificuldades em, pelo menos, uma das operações básicas. Isso se dá, ao ensino defasado nos anos iniciais, que é consequência do ensinar Matemática sem explicar a origem e as finalidades dos conceitos. A humanidade está em constante evolução e a educação deve sempre se renovar para acompanhar esse progresso.

Esta foi uma pesquisa simples com resultados bastante coerentes que nos permitiu enxergar a importância do ensino da matemática nos anos iniciais e nos mostrou que um dos principais motivos da dificuldade de compreender os conteúdos matemáticos em sala de aula, é a forma como ela é repassada durante a alfabetização matemática.

Assim, podemos concluir que, é fundamentos que os professores das series iniciais tenham uma formação sólida no conhecimento matemático, os quais precisam ser repassados aos alunos de forma inovadora. Com isso, espera-se que nos primeiros anos de escolarização os alunos desenvolvam conhecimentos necessários que colaborem com a aprendizagem da Matemática futura.

\section{REFERÊNCIAS}

Metade dos alunos brasileiros não sabe fazer contas, nem entende o que lê. Disponível em: <https://www.huffpostbrasil.com/2016/12/06/metade-dos-alunos-brasileiros-nao-sabefazer-contas-nem-entende_a_21700801/> Acesso em: 09 de Outubro de 2018

DANYLUK, Ocsana. Alfabetização matemática: as primeiras manifestações da escrita infantil. Porto Alegre: Sulina, 1998.

PIRES, V. E. O. O ensino da matemática nos dias atuais. Disponível em: $<$ http://www.somatematica.com.br/coluna/coluna_usuario.html $>$ Acesso em: 09 de Outubro de 2018.

MORAIS, G.de; DAHER, A. Os desafios da aprendizagem Matemática: 2007. 45 f. Monografia (Graduação em Matemática) - Centro Universitário de Lavras - UNILAVRAS, Lavras. 